\title{
Relationship between soluble F11 receptor and ischemic heart disease in hemodialysis patients
}

\author{
Seham Bakry and Ahmed Bahgat El-demery \\ Departments of Internal Medicine, Cairo University and Biochemistry, Faculty of Medicine 6th October University, Cairo, Egypt.
}

\begin{abstract}
Background: Cardiovascular disease is a major cause of morbidity and mortality in hemodialysis patients, there is increasing evidence that platelets are major contributors to atherosclerosis, which is mediated through F11 receptors.

Methods: Our study included 40 hemodialysis patients divided into two groups:

Group 1: included 20 hemodialysis patients with ischemic heart disease (IHD), Group 2: included 20 hemodialysis patients without ischemic heart disease, they were compared with 20 age and sex matched controls, soluble F11 receptor (sF11R) and high sensitivity C-reactive protein (hs-CRP) were measured by enzyme-linked immunosorbent assay (ELISA).

Results: sF11R was significantly higher in hemodialysis patients than controls; it showed significant difference between group 1, group 2 patients and controls. sF11R showed significant positive correlation with hs-CRP . Conclusion: sF11R can be considered a marker of IHD in hemodialysis patients.
\end{abstract}

Key words: Hemodialysis; IHD-sF11R; atherosclerosis.

\section{Introduction}

Since $1960_{\mathrm{S}}$, cardiovascular disease is the most common cause of death in patients with ESRD. The cardiovascular mortality rate in ESRD patients on dialysis is approximately 10 to 20 times higher than in the general population [1].

Acute myocardial infarction accounted for 14 deaths per 1000 patient/year whereas arrhythmia and sudden death accounted for 46.5 deaths per 1000 patient/year [2].

Correspondence and offprint requests to: Dr. Seham Bakry, Departments of Internal Medicine, Cairo University and Biochemistry, Faculty of Medicine 6th October University, Cairo, Egypt.
The probability that a dialysis patient will develop ischemic heart disease or cardiac failure is about $20 \%$ per year [3]. Many risk factors predispose to ischemic heart disease in renal failure patients such as systemic arterial hypertension [4], diabetes mellitus [5], dyslipidemias [6], inflammation [7], and vascular calcification [8].

Many inflammatory markers are up regulated in hemodialysis patients as interleukin 6 , and high sensitivity C - reactive protein, so these markers link the pathogenesis of atherosclerosis to chronic inflammation [9]. It is now accepted that platelets contribute to acute or chronic inflammatory events, leading to atherosclerotic lesion formation. There is a growing body of evidence showing that the interaction between platelets and endothelial cells contributes significantly to the pathogenesis of atherosclerosis [10].

Platelet adhesion to the inflamed endothelium triggers the formation of thrombi leading to atherosclerotic lesions [11].

A key molecule identified as critical for platelet adhesion to an activated endothelial surface is the F11 receptor (F11R) [12].

F11 receptor (F11R/JAM-A) is a member of the immunoglobulin super family. The F11 receptor (F11R) was described first in human platelets in 1990 [12]. In 1998, amino acid sequences homologous to the F11R were found in a protein present within tight junctions of endothelial cells [13] where the molecule was called Junctional Adhesion Molecule (JAM), F11R is a $32 / 35$ $\mathrm{kDa}$ protein duplex that serves as a receptor for a functional monoclonal antibody that activates platelets, This monoclonal antibody binds to the platelet F11 receptor resulting in granule secretion and aggregation [14].

A potential mechanism of finding a soluble fragment of the extracellular domain of F11R is that F11R is shed from endothelial cells and/or platelets through a pathway involving enzymatic cleavage at a site in close proximity to the membrane, resulting in the release of the extracellular domain of F11R into the circulation [15]. 


\section{Material and methods}

The present study included 40 chronic renal failure patients on regular hemodialysis from dialysis center at Cairo University in the period from May 2008 to June 2009.

Patients receive dialysis sessions for 4 hours, three times weekly through arteriovenous fistula, mean age \pm SD was $47.5 \pm 10.4,50 \%$ were males and $50 \%$ were females. Duration of dialysis ranged from 1 year to 15 years with (mean \pm SD) 17.1 \pm 3.5 years. Patients receive heparin during dialysis sessions. Patients were excluded if they take drugs which inhibit platelet function as asprin, clopedrogrel. None of our patients were diabetics.

They were divided into two groups:

Group 1: Included 20 patients who are known to have coronary artery disease, which was diagnosed on the basis of history, ECG, echocardiography, coronary angiography which was performed in selected patients.

Group 2: Included 20 patients without ischemic heart disease (IHD).

They were compared with 20 age and sex matched healthy controls.

All patients were subjected to the followings:

- Full history taking.

- Full clinical examination.

- Pre dialysis serum creatinine, blood urea, calcium $(\mathrm{Ca})$, phosphorus $(\mathrm{P})$, calcium $\times$ phosphorus $(\mathrm{Ca} \times \mathrm{P})$ product, hemoglobin, platelet count.

- High sensitivity C-reactive protein (hs-CRP) by Enzyme linked Immunosorbent assay technique (ELISA) [16].

- Soluble F11 receptor level was measured in plasma by sandwich ELISA using commercially available ELISA kits, F11R (R\&D Systems; and BD Biosciences, San Jose, California) according to manufacturer's instructions [17].

- ECG.

- Echocardiography.

- Coronary angiography in selected patients with ischemic heart disease.

\section{Statistical analysis}

Analysis of data was done by IBM computer using SPSS (statistical program for social science version 12) as follows

- Chi-square test was used to compare qualitative variables between groups.

- Unpaired t-test was used to compare quantitative variables, in parametric data ( $\mathrm{SD}<50 \%$ mean)

- One way ANOVA (analysis of variance) test was used to compare more than two groups in parametric quantitative data.

- Correlation coefficient test was used to rank different variables against each other positively or inversely.
- ROC (receiver operator characteristic curve was used to find out the best cut off value of certain variable).

\section{Results}

Table 1. Laboratory data of hemodialysis (HD) patients.

\begin{tabular}{lll}
\hline Laboratory data & Mean \pm SD & Range \\
\hline & & \\
Platelets $(\mathrm{x} 1000 / \mathrm{ml})$ & $231 \pm 78$ & $122-387$ \\
Hemoglobin $(\mathrm{gm} / \mathrm{dl})$ & $9.7 \pm 2.5$ & $6-15$ \\
Calcium $(\mathrm{mg} / \mathrm{dl})$ & $8.1 \pm 0.6$ & $7.2-9$ \\
Phosphorus $(\mathrm{mg} / \mathrm{dl})$ & $3.8 \pm 1.3$ & $2.7-4.6$ \\
Ca $\times$ P & $20 \pm 2.3$ & $18-25$ \\
Urea $(\mathrm{mg} / \mathrm{dl})$ & $130 \pm 23$ & $70-150$ \\
Creatinine $(\mathrm{mg} / \mathrm{dl})$ & $9.3 \pm 2.1$ & $5.1-15.2$ \\
& & \\
\hline
\end{tabular}

Table 2. Comparison between HD patients and controls regarding sF11R.

\begin{tabular}{llll}
\hline & HD patients & Controls & P-value \\
& & \\
\hline $\mathrm{sF} 11 \mathrm{R}(\mathrm{pg} / \mathrm{ml})$ & $92.6 \pm 31$ & $30.1 \pm 6$ & $<0.01$ \\
\hline
\end{tabular}

Table 2 shows that there was statistically significant difference in SF11R between HD patients and controls.

Table 3. Comparison between IHD, non IHD hemodialysis patients and controls regarding sF11R and hs-CRP.

\begin{tabular}{lllll}
\hline Variable & IHD & Non IHD & Controls & P-value \\
& & & & \\
sF11R(pg/ml) & $101 \pm 29$ & $83 \pm 32$ & $30.1 \pm 6$ & $<0.01$ \\
hs-CRP(mg/dl) & $5.74 \pm 1.36$ & $3.12 \pm 1.15$ & $0.83 \pm 0.20$ & $<0.01$ \\
& & & & \\
\hline
\end{tabular}

Table 3 shows that there were statistically significant differences in $\mathrm{sF} 11 \mathrm{R}$ and hs-CRP between HD patients with IHD, HD patients without IHD and controls.

Table 4. Correlation between sF11R and clinical and laboratory data.

\begin{tabular}{llc}
\hline \multirow{2}{*}{ Variable } & \multicolumn{2}{c}{ sF11R } \\
\cline { 2 - 3 } & $\mathrm{r}$ & $\mathrm{p}$-value \\
\hline & & $>0.05$ \\
Age & 0.04 & $>0.05$ \\
Duration of the disease & 0.13 & $>0.05$ \\
Hypertension & 0.09 & $<0.05$ \\
IHD & 0.40 & $>0.05$ \\
Platelets & -0.12 & $<0.05$ \\
Hemoglobin & -0.15 & $>0.05$ \\
Calcium & -0.37 & $>0.05$ \\
Phosphorus & -0.09 & $>0.05$ \\
Ca×P & -0.13 & $>0.05$ \\
Urea & 0.35 & $<0.05$ \\
Creatinine & 0.30 & \\
hs-CRP & 0.39 & \\
& & \\
\hline
\end{tabular}


Table 4 shows that sF11R had significant positive correlation with the presence of ischemic heart disease and hs-CRP, and significant negative correlation with serum calcium level, with no significant correlation with other clinical and laboratory findings.

Table 5. Sensitivity, specificity, PPV, NPV and accuracy of sF11R.

\begin{tabular}{ll}
\hline Variables & P-value \\
& \\
\hline & \\
Best cut-off value & $40 \mathrm{pg} / \mathrm{ml}$ \\
Sensitivity & $97.5 \%$ \\
Specificity & $95 \%$ \\
PPV & $97.5 \%$ \\
NPV & $95 \%$ \\
Accuracy & $96 \%$ \\
& \\
\hline
\end{tabular}

Table 5 shows that sF11R is considered a valid marker for prediction of ischemic heart disease in hemodialysis patients with high sensitivity, specificity, and accuracy.

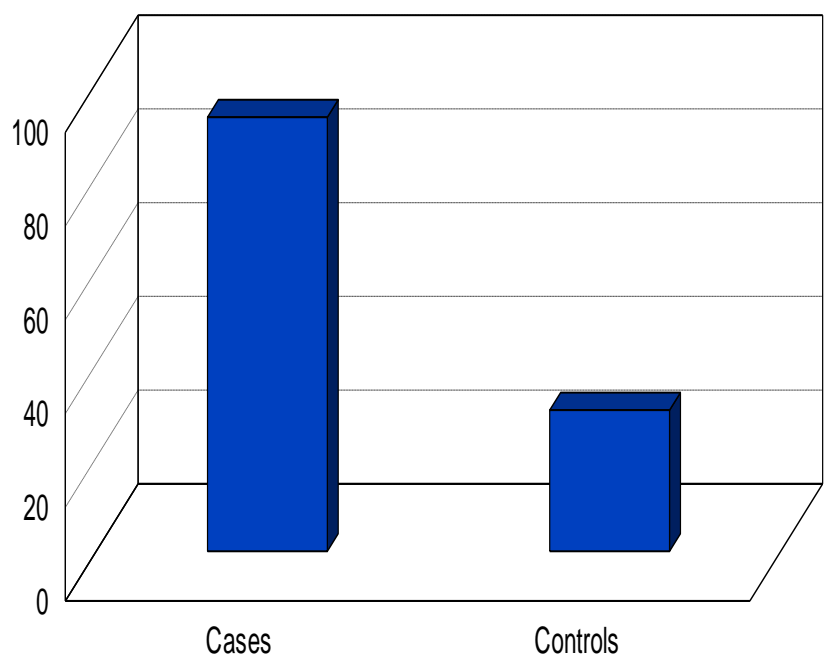

Fig. 1. Comparison between cases and controls as regard sF11R.

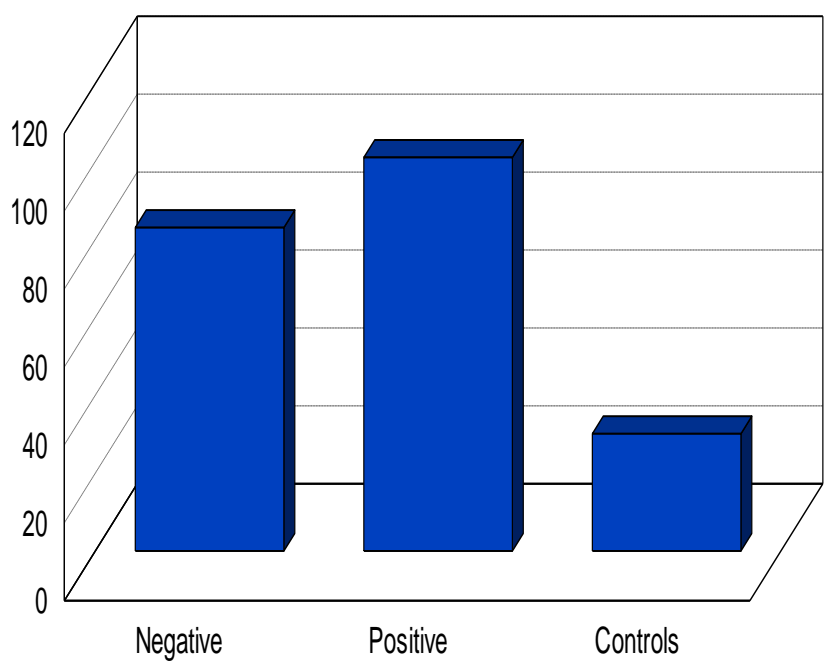

Fig. 2. Comparison between IHD, non IHD hemodialysis patients and controls as regard sF11R.

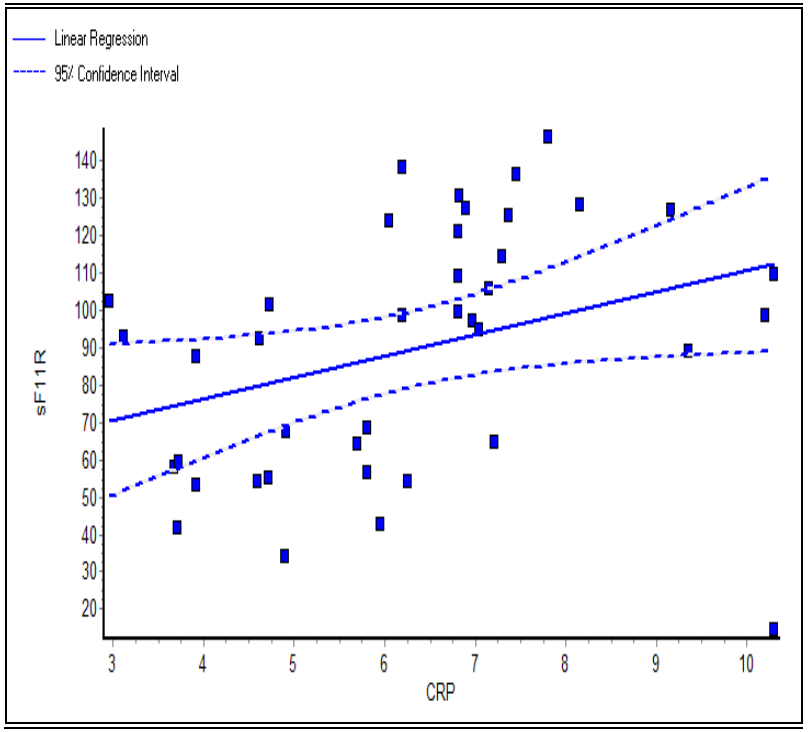

Fig. 3. Correlation between $\mathrm{sF} 11 \mathrm{R}$ versus hs-CRP among the studied cases by linear regression curve.

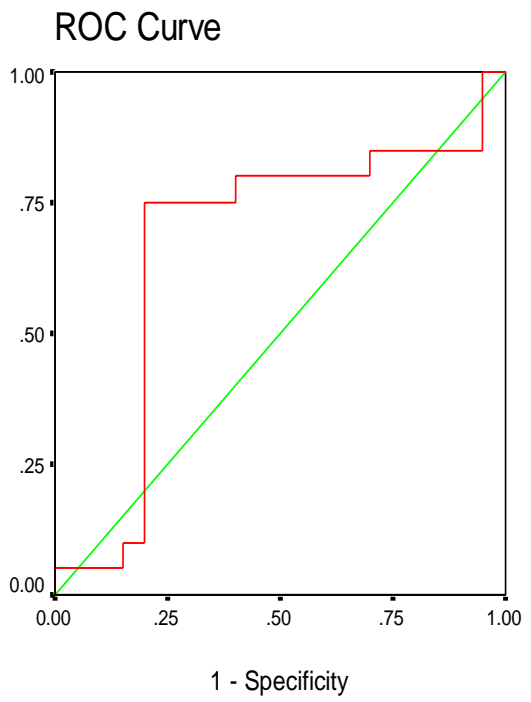

Fig. 4. Receiver operator characteristic curve for $\mathrm{sF} 11 \mathrm{R}$. Area under the curve $=97 \%$.

Upon one year follow up, 6 out of the 20 dialysis patients with IHD developed myocardial infarction or unstable angina, for which they were admitted to coronary care unit, 4 of these patients died, and 2 patients improved by treatment. Their (mean $\pm \mathrm{SD}$ ) $\mathrm{sF} 11 \mathrm{R}$ was $(123.73 \pm 18.87$ ), which is higher but statistically non significant than those with IHD patients who did not develop recent cardiac events (115.58 \pm 16.24$)$.

\section{Discussion}

Cardiovascular disease is a major cause of morbidity and mortality in haemodialysis patients, there is increasing evidence that platelets are involved in atherosclerotic plaque formation via F11R [18]. The activation of F11R appears to trigger two pathways: The 
first includes cross linking of the F11R to the Fc $\gamma \mathrm{R} 11$ and plays a role in the aggregation of platelets but not adhesion [19], The second pathway involves the binding of the constitutively expressed F11R of platelets to the up-regulated F11R located on the luminal surface of the inflamed endothelium through hemophilic interactions [20].

Activation of Fl IR has been found to cause sensitization of platelets, increasing the platelet reactivity to circulating platelet receptor agonists such as adenosine diphosphate and thrombin [21].

Subsequently, following the adhesion of platelets to the inflamed endothelium through F11R, subthreshold concentrations of naturally circulating agonists would be expected to cause stable buildup of platelet plaques, thereby contributing to atherosclerosis [19].

Our study revealed that $\mathrm{sF} 11 \mathrm{R}$ was significantly higher in hemodialysis patients than in normal controls; it showed significant difference between hemodialysis patients with IHD, hemodialysis patients without IHD and normal controls.

sF11R showed significant positive correlation with inflammatory marker hs- CRP, and significant negative correlation with serum calcium, while no significant correlation was found with other study variables, including age, duration of the disease, presence of hypertension, phosphorus, $\mathrm{Ca} \times \mathrm{P}$ product, platelet count or hemoglobin level.

Salifu and his colleagues [15] reported that sF11 R level was significantly higher in hemodialysis patients than normal controls, sF11R had significant positive correlation with inflammatory markers as tumor necrosis factor $\alpha$ (TNF- $\alpha$ ), interleukin-6 (IL-6), and interleukin10 (IL-10), but no significant correlation was found between $\mathrm{sF} 11 \mathrm{R}$ and hs-CRP.

ROC curve was constructed and revealed that SF11R can be considered as sensitive and specific marker of IHD in hemodialysis patients with $97.5 \%$ sensitivity and $95 \%$ specificity.

Follow up of our patients for one year revealed that 6 patients of IHD group developed acute coronary syndrome 4of them died, these patients had higher levels (although statistically not significant) of s F11R than IHD patients who did not develop cardiac events through one year follow up.

\section{Conclusion}

$\mathrm{sF11R}$ can be considered as sensitive and specific marker of IHD in hemodialysis patients, it could be also a marker of cardiovascular morbidity and mortality, but further studies are needed including larger number of patients and longer periods of follow up.

\section{References}

1. Bleyer AJ, Hartman J, Brannon PC, et al.: Characteristics of sudden death in hemodialysis patients. Kidney Int. 2006; 69(12):2268-2273.

2. Herzog CA.: Sudden cardiac death and acute myocardial infarction in dialysis patients: perspectives of a cardiologist. Semin Nephrol. 2005; 25(6):363-366.

3. Murphy SW, Parfrey PS.: Screening for cardiovascular diseases in dialysis patients. Curr Opin Nephrology hypertension. 2007; 25:532-540.

4. Bongartz LG, Cramer MJ, Doevendans PA, et al.: The severe cardiorenal syndrome: "Guyton revisited". Eur Heart J. 2005; 26(1):11-17.

5. Chen J, Muntner P, Hamm LL, et al.: The metabolic syndrome and chronic kidney disease in U.S. adults. Ann Intern Med. 2004; 140(3):167-174.

6. Trevisan R, Dodesini AR, Lepore $\mathrm{G}$ el al.: Lipids and renal disease. J Am Soc Nephrol. 2006; 17(4 suppl 2):S145-147.

7. Reuben DB, Ferrucci L, Wallace R, at al.: The prognostic value of serum albumin in healthy older persons with low and high serum interleukin-6 (IL-6) levels. J Am Geriatr Soc. 2000; 48(11):14041407.

8. Burke AP, Taylor A, Farb A, et al.: Coronary calcification: Insights from sudden coronary death victims. Cardiol. 2000; 89 (suppl 2):49-53

9. Honda H, Qureshi AR, Heimburger O, et al.: Serum albumin, Creactive protein, interleukin 6 , and fetuin a as predictors of malnutrition, cardiovascular disease, and mortality in patients with ESRD. Am J Kidney Dis. 2006; 47:139-148

10. Ruggeri ZM.: Platelets in athero-thrombosis. Nat Med. 2002; 8:1227-1234.

11. Gawaz M, Langer H, May AE, et al.: Platelets in inflammation and atherogenesis. J Clin Invest. 2005; 115:3378-3384.

12. Kornecki E, Walkowiak B, Naik UP,et al.: Activation of human platelets by a stimulatory monoclonal antibody. J Biol Chem. 1990; 265:10042-10048.

13. Santoso S, Sachs UJ, Kroll H, et al.: The junctional adhesion molecule 3 (JAM-3) on human platelets is a counter receptor for the leukocyte integrin Mac-1. J Exp Med. 2002; 196:679-691.

14. Babinska A, Azari BM, Salifu MO, et al.: The F11 receptor (F11 $\mathrm{R} / \mathrm{JAM}-\mathrm{A}$ ) in athero-thrombosis: Over expression of F11R in atherosclerotic plaques. Thromb haemost .2007; 97(2):272- 281.

15. Salifu MO Kolff O, Murty P, et al.: Relationship between the soluble F11 receptor and markers of inflammation in hemodialysis patients. J Invest Med. 2007; 55 (3):115-119.

16. Votila M, Ruslanti E, Engull E.: Two site sandwich enzyme immunoassay with monoclonal antibodies. Immunol Methods.1981; 42:11-15.

17. Erdal C, Elizabeth K, Babinski A, et al.: Association of plasma level of F11 receptor/ Junctional adhesion molecule-A (F11R/JAM-A) with human atherosclerosis.J Am Coll Cardiol. 2007; 50:1768-1776.

18. Massberg S, Brand K, Gruner S.: A critical role of platelets adhesion in the initiation of atherosclerotic lesion formation. $\mathrm{J}$ Exp Med. 2002; 196:887-896.

19. Sobocka MB, sobocki T, Babinska A,et al.: Signaling pathways of the F11 receptor in human platelets. J Receptor signal transduction Res. 2004; 24 (1-2):85-105.

20. Sobocka B, Sobocki T, Banerjee P, et al.: Cloning of the human platelet F11 receptor: a cell adhesion molecule member of the immunoglobulin super family involved in platelet aggregation. Blood .2000; 95:2600-2609.

21. Gawaz M.: Platelets at the onset of atherosclerosis. Blood cells Mol Dis.2006; 36:202-210. 